\title{
PENGGUNAAN SISTEM AKUAPONIK DENGAN JENIS TANAMAN YANG BERBEDA TERHADAP PERTUMBUHAN DAN KELANGSUNGAN HIDUP IKAN MAS (Cyprinus Carpio)
}

\author{
Juli Prahesti ${ }^{1}$, Rahmad Jumadi ${ }^{2}$, Andi Rahmad Rahim ${ }^{2}$ \\ ${ }^{1}$ Mahasiswa Program Studi Akuakultur, Fakultas Pertanian Universitas Muhammadiyah Gresik. \\ ${ }^{2}$ Dosen Fakultas Pertanian Universitas Muhammadiyah Gresik. \\ Email : Julij7149@gmail.com ; Phone No. +6281238525528
}

\begin{abstract}
Common carp (Cyprinus carpio) is one type of freshwater fish that develops very rapidly as a commercial fish. The purpose of this study was to determine the best plant species in aquaponic systems in increasing optimal growth of common carp (Cyprinus carpio). This study used a completely randomized design (RAL) with 4 treatments and 3 replications. Analysis of variance (ANOVA) was used to see significant differences in treatment. Composition of treatment $\mathrm{K}$ (without plants), A (kale), B (lettuce), C (pakcoy). The main observation variables include absolute weight growth, absolute length, daily growth rate, survival rate and feed conversion ratio. The results of variance analysis (ANOVA) showed very significant differences in absolute length and survival variables. Absolute weight, daily growth rate and FCR in the study did not show any real differences. The highest absolute weight growth, daily growth rate, and feed conversion ratio are perlakaun $\mathrm{K}$ (without plants) $(1,19) \mathrm{g},(1,59) \mathrm{cm}$ and $(3,48) \mathrm{g}$. The highest absolute length is treatment $\mathrm{C}$ (pakcoy) which is $(0.97) \mathrm{cm}$. A good survival rate is B (lettuce) treatment, that is $(60.00 \%)$.
\end{abstract}

Keywords: Common Carp, Growth, Survival and FCR

\begin{abstract}
ABSTRAK
Ikan mas (Cyprinus carpio) merupakan salah satu jenis ikan air tawar yang berkembang sangat pesat sebagai ikan komersial. Tujuan penelitian ini untuk menentukan jenis tumbuhan yang terbaik pada sistem akuaponik dalam meningkatkan pertumbuhan optimal ikan Ikan mas (Cyprinus carpio) Penelitian ini menggunakan Rancangan Acak Lengkap (RAL) dengan 4 perlakuan dan 3 ulangan. Analisis sidik ragam (ANOVA) digunakan untuk melihat perbedaan nyata perlakuan. Susunan perlakuan K (tanpa tanaman), A (menggunakan tanaman kangkung), B (menggunakan tanaman selada),C (menggunakan pakcoy). Variabel pengamatan utama meliputi pertumbuhan bobot mutlak, panjang mutlak, laju pertumbuhan harian, tingkat kelangsungan hidup dan Rasio konversi pakan. Hasil analisis sidik ragam (ANOVA) menunjukkan perbedaan sangat nyata pada variabel panjang mutlak dan kelangsungan hidup. Bobot mutlak, laju pertumbuhan harian dan FCR pada penelian tidak menunjukkan perbedaan nyata. Rata-rata pertumuhan bobot mutlak, laju pertumbuhan harian dan rasio konversi pakan yang tertinggi adalah perlakaun K (tanpa tanaman) $(1,19) \mathrm{g}$, $(1,59) \mathrm{cm}$ dan $(3,48) \mathrm{g}$. Panjang mutlak yang
\end{abstract}


tertinggi adalah perlakuan $\mathrm{C}$ (pakcoy) yakni $(0,97) \mathrm{cm}$. Tingkat kelangsungan hidup yang baik adalah perlakuan B (selada) yakni $(60,00 \%)$.

Kata kunci : Ikan Mas, Perumbuhan, Kelangsungan Hidup dan FCR

\section{PENDAHULUAN}

Ikan mas (Cyprinus carpio) merupakan salah satu jenis ikan air tawar yang berkembang sangat pesat sebagai ikan komersial. Ikan mas merupakan salah satu komoditi yang memiliki nilai ekonomis penting dengan target penjualan di dalam dan luar negeri. Saat ini teknologi budidaya ikan mas sudah dikuasai mulai dari pembenihan sampai pembesaran, sehingga produksi ikan mas mencapai 46,50\% pada tahun 2003 (Djarijah, 2001).

Permasalahan yang biasa dihadapi dalam budidaya ikan mas adalah kualitas air. Kualitas air pemeliharaan dapat menurun dengan cepat karena sisa pakan yang mengedap di dasar kolam, feses dan buangan metabolit. Hal ini tampak dari menurunnya kualitas air akibat peningkatan $\mathrm{pH}$ air yang terlalu cepat dan tingginya kadar amonia selama pemeliharaan. Kualitas air tersebut menyebabkan keracunan atau kekurangan oksigen bagi ikan yang di budidaya.

Salah satu upaya yang dapat dilakukan untuk menanggulangi permasalahan penurunan kualitas air karena adanya akumulasi, mineralisasi dan nitrifikasi bahan organik adalah dengan mengaplikasikan sistem resirkulasi akuakultur dengan teknologi biofiltrasi dalam budi daya ikan. Penggunaan sistem ini secara umum mempunyai beberapa kelebihan yaitu: penggunaan air persatuan waktu relatif lebih rendah, fleksibilitas lokasi budi daya dan budi daya yang terkontrol, kebutuhan ruang/lahan relatif kecil, kemudahan dalam mengendalikan, memelihara dan mempertahankan suhu serta kualitas air (Helfrich dan Libey, 2000 dalam Putra 2010).

\section{TINJAUAN PUATAKA}

Ikan mas termasuk golongan ikan yang aktif bila di lihat dari makan ikan tersebut, karena ikan mas akan bergerak cepat kearah pakan dan dengan cepat pula menangkap pakan. Ikan mas lebih agresif, tetapi bila sudah kenyang ikan mas akan masuk kedalam air (Khairuman , 2008).

Ikan mas dapat hidup dan berkembang baik pada ketinggian 150 - $600 \mathrm{~m}$ di atas permukaan laut (dpl) dengan suhu optimal $25-30{ }^{\circ} \mathrm{C}$., $\mathrm{pH}$ antara $7-8$ dan termasuk ikan pemakan tumbuhan dan hewan (omnivore) (Narantaka, 2012).

Menurut Diver (2006) akuaponik adalah kombinasi akuakultur dan hidroponik untuk memelihara ikan dan tanaman dalam satu sistem yang saling terhubung. Limbah yang dihasilkan oleh ikan digunakan sebagai pupuk untuk tanaman (Wahap et al. 2010). Interaksi antara ikan dan tanaman menghasilkan lingkungan yang ideal untuk tumbuh sehingga lebih produktif dari metode tradisional (Rakocy et al. 2006).

Pada sistem akuaponik, aliran air kaya nutrisi dari media pemeliharan ikan digunakan

untuk menyuburkan tanaman hidroponik. Hal ini baik untuk ikan karena akar tanaman dan rhizobakter mengambil nutrisi dari air. Nutrisi yang berasal dari feses, urin dan sisa pakan ikan 
adalah kontaminan yang menyebabkan meningkatnya kandungan racun pada media pemeliharaan, tetapi air limbah ini juga menyediakan pupuk cair untuk menumbuhkan tanaman secara hidroponik. Sebaliknya, media hidroponik berfungsi sebagai biofilter, yang akan menyerap ammonia, nitrat, nitrit dan posfor sehingga air yang sudah bersih dapat dialirkan kembali ke media pemeliharaan (Diver, 2006).

\section{METODOLOGI}

Alat: pipa dengan ukurang 3 inci panajang $20 \mathrm{~cm}$, bak, selang, aerator, pompa, kayu, alat tulis, $\mathrm{pH}$ meter.DO meter, timbangan, pengaris, nampan dan tali rafiah. Bahan: rockwool dengan ukuran 2x2x2cm, benih ikan mas, benih tanaman (kangkung, selada dan pakcoy) dan pelet.

Penelitian dilakukan dengan metode eksperimental dengan Rancangan Acak Lengkap (RAL) yang terdiri dari 12 unit percobaan dengan 4 perlakuan dan 3 kali ulangan. Perlakuan $\mathrm{K}$ (control), A(kangkung), B(selada) dan C(pakcoy)

Variabel utama yang diamati di penelitian penggunaan jenis tanaman yang berbeda meliputi : pertumbuhan, kelangsungan hidup, FCR (Food Convertion Ratio) dan kualitas air dengan variable tambahan yaitu tinggi tanaman, bobot akar dan bobot brangkasan. Pengamatan pertumbuhan diantara lain bobot mutlak dan laju pertumbuhan harian dilakukan pengambilan sampel ikan mas setiap seminggu sekali. Hasil penelitian menggunakan analisis sidik ragam (ANOVA). Jika analisi data menunjukkan perbedaan nyata maka dilanjutkan uji BNJ (Beda nyata jujur).

\section{a. Pertumbuhan Bobot (gram)}

Pertumbuhan bobot mutlak (W) dihitung menggunakan rumus Wijayanti (2010) :

$$
\boldsymbol{W}=\boldsymbol{W t}-\boldsymbol{W 0}
$$

\section{Keterangan :}

W : pertumbuhan bobot $(\mathrm{g})$

Wt : Bobot rata-rata ikan pada waktu akhir (g)

W0 : bobot rata-rata ikan pada waktu awal penelitian (g)

\section{b. Laju Pertumbuhan Spesifik}

Pertambahan berat dan laju pertumbuhan dihitung menggunakan metode Ogunji et al. (2008) menggunakan perhitungan sebagai berikut :

$$
S G R=\frac{\operatorname{InWt}-\operatorname{InWo}}{t} x 100 \%
$$

\section{Keterangan :}

SGR : Laju pertumbuhan spesifik (\%)

Wt : Berat awal ikan (g)

Wo : Berat akhir ikan (g) 
t : Jumlah hari selama pemberian pakan (hari)

\section{c. Pertumbuhan Panjang Mutlak (cm)}

Pertumbuhan panjang mutlak adalah gambaran perubahan panjang rata-rata individu pada tiap perlakuan dari awal hingga akhir pemeliharaan. Pertumbuhan panjangdihitung dengan rumus dari Effendie (1979):

$$
P m=L t-L o
$$

Keterangan :

$\mathrm{Pm}$ : pertumbuhan panjang mutlak $(\mathrm{cm})$

Lt : panjang rata-rata akhir $(\mathrm{cm})$

Lo : panjang rata-rata awal $(\mathrm{cm})$

\section{d. Kelangsungan Hidup (Survival Rate)}

Survival Rate adalah jumlah tingkat kehidupan ikan dari penebaran hingga akhir pemeliharaan. Adapun rumus perhitungan tingkat kelangsungan hidup (SR) adalah sebagai berikut (Effendi, 1979) :

$$
S R=\left(\frac{N t}{N 0}\right) \times 100 \%
$$

Keterangan:

SR : Survival Rate / sintasan (\%)

$\mathrm{Nt} \quad$ : jumlah ikan yang hidup di akhir penelitian (ekor)

NO : jumlah ikan yang hidup di awal penelitian (ekor)

\section{HASIL DAN PEMBAHASAN}

\section{a. Bobot Mutlak (g)}

Hasil pengamatan pertumbuhan bobot mutlak ikan mas (Cyprinus carpio) yang dilakukan selama 35 hari dengan mengunakan media akuaponik adalah sebagai berikut : 


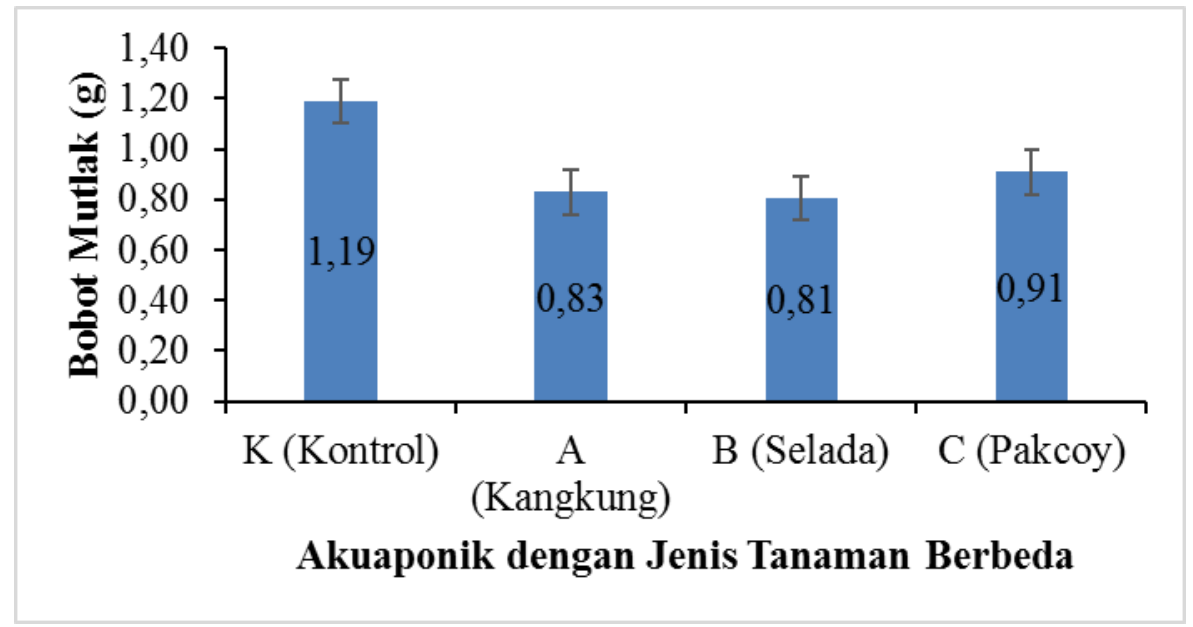

Dari Gambar di atas menunjukkan, rata-rata bobot mutlak ikan mas selama penelitian dengan kisaran yaitu 0,81 - 1,19 g. Dengan perlakuan tertinggi didapatkan pada perlakuan K (Kontrol) dan terendah pada perlakuan B (tanaman selada). Dari Hasil Analisis Statistik Analysis of Variance (ANOVA) (Lampiran1) menunjukkan bahwa, akuaponik dengan jenis tanaman yang berbeda tidak memberikan pengaruh yang nyata atau non signifikan terhadap peningkatan bobot mutlak (g) ikan mas (p>0,05) sehingga tidak dilakukan uji lanjut Tukey (BNJ).

\section{b. Laju pertumbuhan harian (\%)}

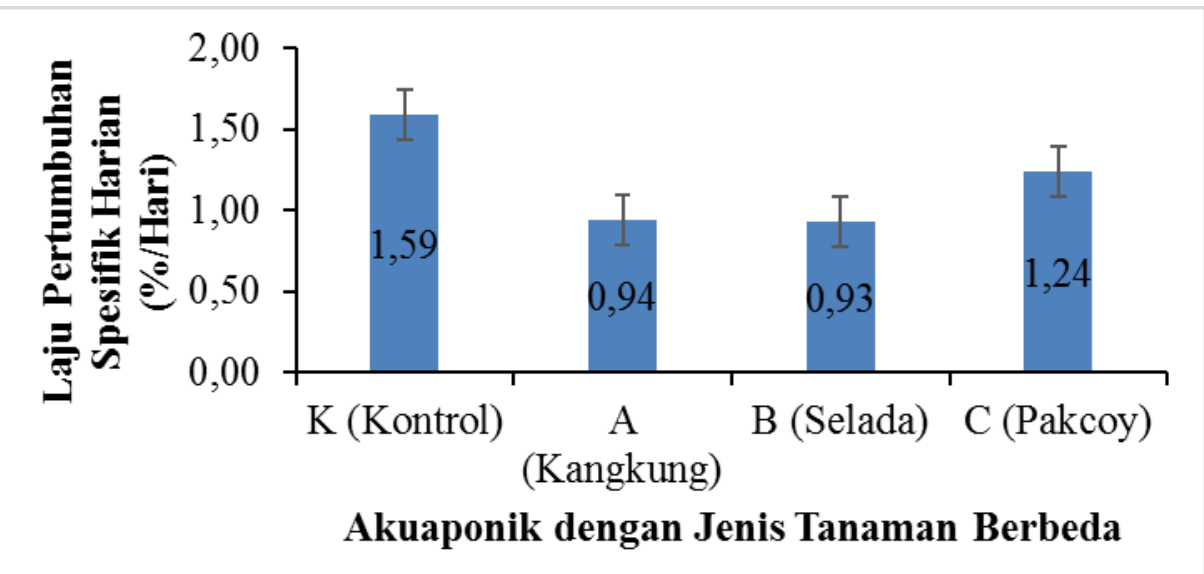

Dari Gambar di atas menunjukkan, rata-rata Laju Pertumbuhan Harian (\%/Hari) ikan mas selama penelitian dengan kisaran yaitu 0,93 - 1,59 \%/Hari. Dengan perlakuan tertinggi d hasil uji Analysis Of Varience ANOVA hasil uji Analysis Of Varience ANOVA idapatkan pada perlakuan K (Kontrol) dan terendah pada perlakuan B (tanaman selada). Dari Hasil Analisis Statistik Analysis of Variance (ANOVA) (Lampiran 3) menunjukkan bahwa, akuaponik dengan jenis tanaman yang berbeda tidak memberikan pengaruh yang nyata atau non signifikan terhadap peningkatan Laju Pertumbuhan Harian(\%/Hari) ikan mas ( $p>0,05)$ sehingga tidak dilakukan uji lanjut Tukey (BNJ). 


\section{c. Panjang Mutlak (cm)}

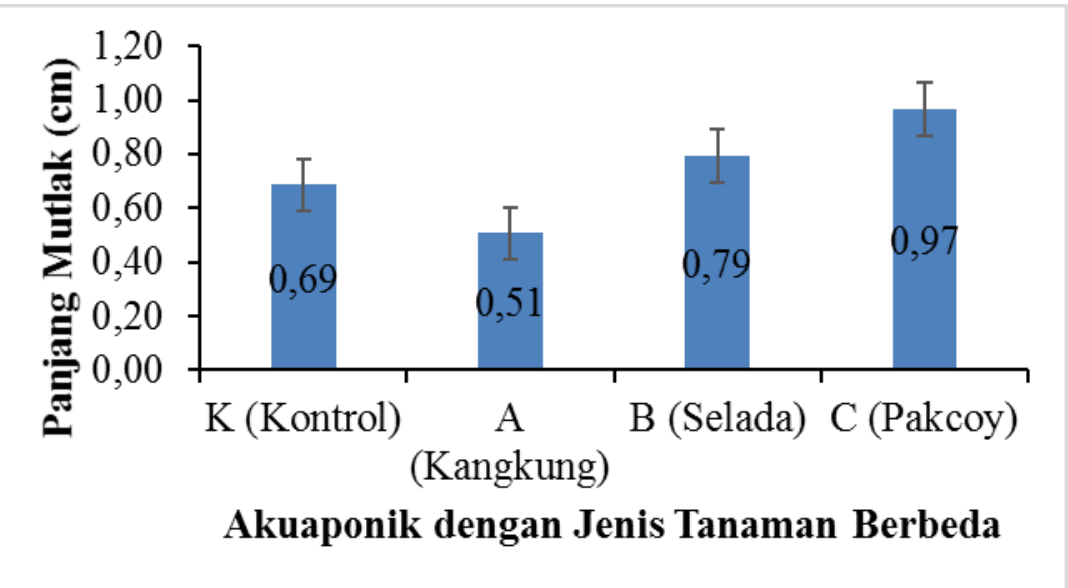

Dari Gambar di atas menunjukkan, rata-rata Laju Panjang Mutlak (cm) ikan mas selama penelitian dengan kisaran yaitu 0,51 - 0,97 $\mathrm{cm}$. Dengan perlakuan tertinggi didapatkan pada perlakuan C (Tanaman Pakcoy) dan terendah pada perlakuan A (Tanaman Kangkung). Dari Hasil Analisis Statistik Analysis of Variance (ANOVA) (Lampiran 2) menunjukkan bahwa, akuaponik dengan jenis tanaman yang berbeda memberikan pengaruh yang nyata atau signifikan terhadap peningkatan Panjang Mutlak $(\mathrm{cm})$ ikan mas $(\mathrm{p}<0,05)$ sehingga dilakukan uji lanjut Tukey (BNJ). Dari hasil uji lanjut Tukey (BNJ) (Lampiran2) menunjukkan bahwa, Perlakuan C (Tanaman Pakcoy) memberikan perbedaan yang signifikan dengan perlakuan A (Tanaman Kangkung) $(\mathrm{p}<0,05)$ dan tidak memberikan perbedaan yang signifikan dengan perlakuan $\mathrm{K}$ (Kontrol) serta perlakuan B (Tanaman Selada) ( $>0$,05). Sedangkan perlakuan K (Kontrol), A (Kangkung) dan B (Selada) tidak memberikan perbedaan yang signifikan antara masing-masing perlakuan $(\mathrm{p}>0,05)$.

\section{d. Kelangsungan Hidup (\%)}

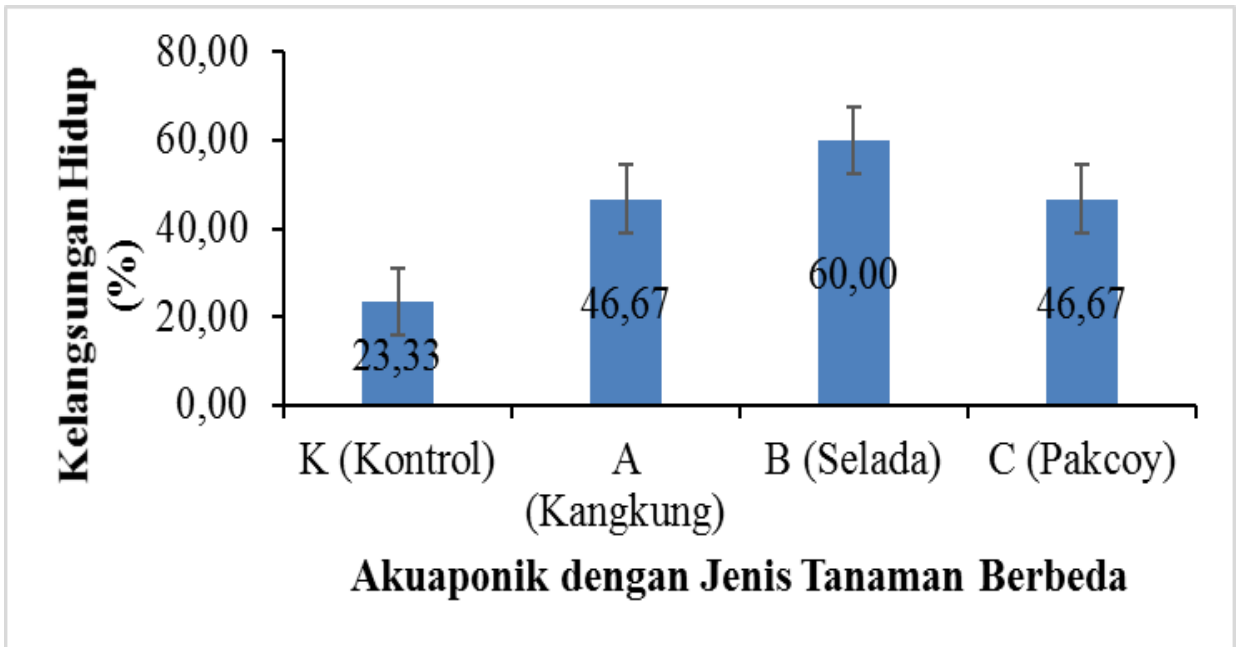


Dari Gambar di atas menunjukkan, rata-rata Kelangsungan Hidup (\%) ikan mas selama penelitian dengan kisaran yaitu 23,33 - 60,00\%. Dengan perlakuan tertinggi didapatkan pada perlakuan B (Tanaman Selada) dan terendah pada perlakuan K (Kontrol). Dari Hasil Analisis Statistik Analysis of Variance (ANOVA) (Lampirann 4) menunjukkan bahwa, akuaponik dengan jenis tanaman yang berbeda memberikan pengaruh yang nyata atau signifikan terhadap peningkatan kelangsungan hidup (\%) ikan mas (cyprinus carpio) $(\mathrm{p}<0,05)$ sehingga dilakukan uji lanjut Tukey (BNJ). Dari hasil uji lanjut Tukey (BNJ) (Lampiran 4) menunjukkan bahwa, Perlakuan B (Tanaman Selada) memberikan perbedaan yang signifikan dengan perlakuan K (Kontrol) $(\mathrm{p}<0,05)$ dan tidak memberikan perbedaan yang signifikan dengan perlakuan A (Kangkung) serta perlakuan C (Tanaman Pakcoy) (p>0,05). Sedangkan perlakuan K (Kontrol), A (Kangkung) dan $\mathrm{C}$ (Pakcoy) tidak memberikan perbedaan yang signifikan antara masing-masing perlakuan $(\mathrm{p}>0,05)$.

\section{e. Rasio Konfersi Pakan}

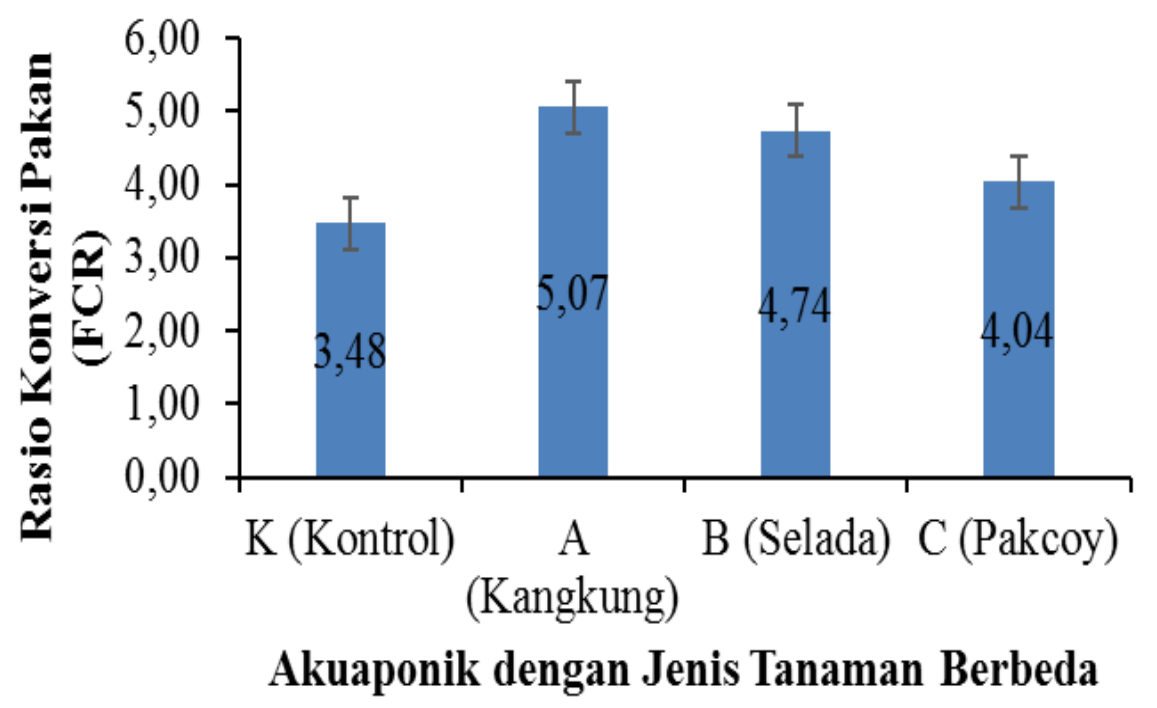

Dari Gambar di atas menunjukkan, rata-rata Rasio Konversi Pakan (FCR) ikan mas selama penelitian dengan kisaran yaitu 3,48 - 5,07. Dengan perlakuan terbaik didapatkan pada perlakuan K (Kontrol) dan yang terburuk pada perlakuan A (tanaman kangkung). Dari Hasil Analisis Statistik Analysis of Variance (ANOVA) (Lampiran 5) menunjukkan bahwa, akuaponik dengan jenis tanaman yang berbeda tidak memberikan pengaruh yang nyata atau non signifikan terhadap peningkatan Rasio Konversi Pakan (FCR) ikan mas (cyprinus carpio) (p>0,05) sehingga tidak dilakukan uji lanjut Tukey (BNJ). 


\section{f. Tinggi Tanaman}

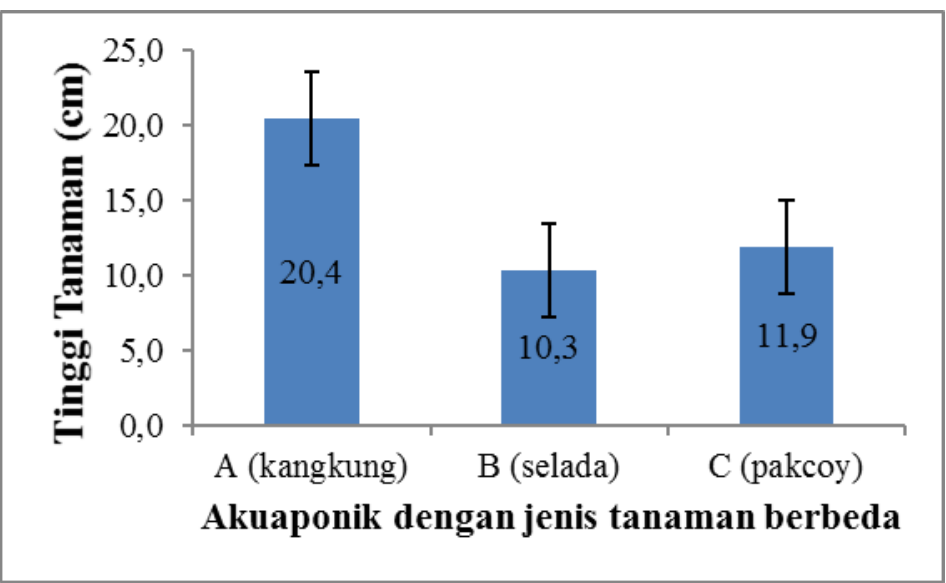

g. Bobot Akar

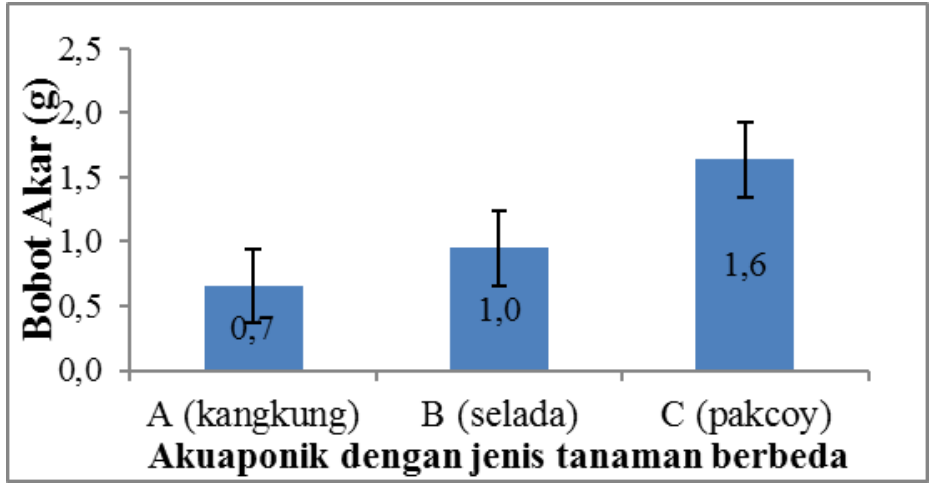

h. Bobot Brangkasan

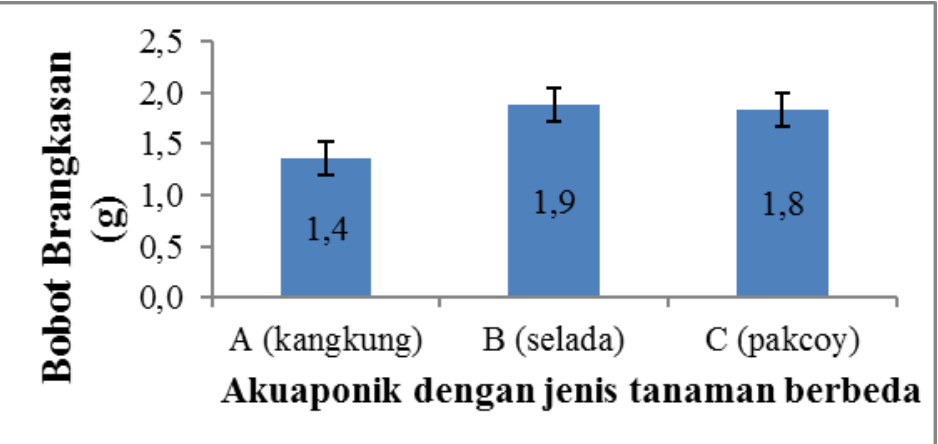


Tinggi tanaman di amati setiap satu minggu sekali dengan cara mengukur dengan sedangkan pengamatan Bobot akar dan bobot brangkasan dengan cara ditimbang dan diamati pada akhir pengamatan yakni pada hari ke 35 .

\section{i. Kualitas Air}

Tabel 3. Hasil Parameter Kualitas Air Ikan Mas (Cyprinus carpio).

\begin{tabular}{ccccc}
\hline Perlakuan & \multicolumn{4}{c}{ Kisaran Kualitas Air Selama Penelitian } \\
\cline { 2 - 5 } & Suhu $\left({ }^{\circ} \mathbf{C}\right)$ & Ph & DO (mg/l) & $\begin{array}{c}\text { Amoniak } \\
(\mathbf{m g} / \mathbf{l})\end{array}$ \\
\hline K (Kontrol) & $28,7-30,3$ & $7-8$ & $4-6,8$ & $0,00-0,25$ \\
A (Kangkung) & $28,1-31,8$ & $7-8$ & $3,5-7,8$ & $0,00-0,04$ \\
B (Selada) & $28,1-30,9$ & $7-8$ & $1,8-7,4$ & $0,00-0,03$ \\
C (Pakcoy) & $28,2-31,6$ & $7-8$ & $3,3-7,5$ & $0,00-0,04$ \\
\hline
\end{tabular}

\section{KESIMPULAN DAN SARAN}

Sistem Akuaponik dengan Jenis tanaman yang berbeda tidak memberi pengaruh nyata terhadap perlakuan A (Kangkung), B (Selada) dan C (pakcoy) pada Pertumbuhan bobot mutlak, laju pertumbuhan harian (SGR) dan FCR.

1. Sistem Akuaponik dengan Jenis tanaman yang berbeda memberi pengaruh nyata terhadap panjang mutlak Pertumbuhan terbaik di tunjukkan oleh perlakuan C (pakcoy) yaitu panjang mutlak dengan (0.97) dan kelangsungan hidup terbaik di tunjukan oleh perlakaun B (selada) yaitu dengan $(60,00 \%)$.

2. Tinggi tanaman kangkung memiliki kisaran (20.4), kisaran bobot akar (1.6) pada tanaman pakcoy dan kisaran bobot brangkasan (1.87) pada tanaman selada.

3. Kisaran kualitas air pada media akuaponik suhu (28.1-31.8), $\mathrm{pH}(7-8), \mathrm{DO}(1.8-7.8)$ dan Amoniak (0.03-0.25).

Adapun saran yang diberikan dari hasil penelitian ini yaitu dengan penelitian lanjutan dapat dilakukan dengan jenis ikan yang berbeda dan jenis tanaman lainnya sebagai media filter.

\section{UCAPAN TERIMAH KASIH}

Terimah kasih disampaikan kepada segenap pihak yang telah membantu dalam pelaksanaan penelitian ini terutama kepada dosen pembimbing Ir. Rahmad Jumadi, M.Kes dan Dr.Andi Rahmad Rahim, S.Pi,.M.Si serta seluruh dosen fakultas pertanian. Teman-teman program studi akuakultur terutama angkatan 2014 yang telah banyak membantu baik material maupun spiritual. 


\section{DAFTAR PUSTAKA}

Djarijah, 2001. Pembenihan Ikan Mas. Kanisius. Yogyakarta.

Diver, S. 2006. Aquaponics - Integration of Hydroponics with Aquaculture. National Sustainable Agriculture Information Service, Australia.

Khairuman, 2008. Buku Pintar Budidaya 15 Ikan Konsumsi. Penerbit Agro Media Pustaka. Jakarta.

Narantaka, A.M.M. 2012. Pembenihan Ikan Mas. Javalitera. Jogjakarta.

Putra, iskandar. 2010. Analisis penyerapan nitrogen dengan biofilter system resirkulasi pada pemeliharaan ikan nila (Oreochromis niloticus). Usulan penelitian. Institute pertanian bogor. Bogor.

Rackocy, J.E., D.S. Bailey., K.A Shultz., W.M. Cole. 2006. Development of an Aquaponic System for the Intensive Production of Tilapia and Hydroponic Vegetables. Universitiy of the Virgin Island Agricultural Experiment Station. Kingshill, U.S Virgin Island.

Wahap, N., A. Estim., A.Y.S Kian., S. Senoo dan S. Mustafa. 2010. Producing Organic Fish and Mint in an Aquaponic System. Borneo Marine Research Institue, Sabah, Malaysia. 